\title{
Brief Analysis of Urban Ecological Civilization Construction
}

\author{
Yanhua Liu \\ School of Marxism, Changchun University of Science and Technology \\ Changchun 130022, China \\ E-mail: liuyanhua@cust.edu.cn
}

Received: December 8, 2011

doi:10.5539/ass.v8n3p265

\author{
Accepted: January 13, $2012 \quad$ Published: March 1, 2012 \\ URL: http://dx.doi.org/10.5539/ass.v8n3p265
}

\begin{abstract}
Ecological civilization city is the advanced stage and senior form of development human residential area and has the characteristics of harmony, sustainability and high efficiency, etc. Ecological civilization construction of the city is the concrete practice of Marxism ecological civilization in the contemporary society, and helps to improve the quality of the urban residents' life, propel the pace of urban modernization construction, upgrade the city taste and increase the competitive force of the city. In order to strengthen urban ecological civilization construction, we have to deal with the relationship between ecological civilization construction and the development of modern industry and agriculture, establish the scientific outlook on development, promote a harmonious social relationship, set up the green consumption concept, strengthen the ecological civilization consciousness of all the citizens, transform of the mode of economic development, and form a strong and vigorous security mechanism.
\end{abstract}

Keywords: Civilization construction, Urban construction, Sustainable development

\section{Theoretical basis of urban ecological civilization construction}

\subsection{Connotation of ecological civilization city}

Ecological civilization city was proposed in the 1970s by the UNESCO in its process of launching and studying the project of "human and biosphere". It is considered to be a system that "coordinates relationship between the economic system and biology in the modern cities, conserves and utilizes all natural resources and energy in a reasonable way, enhances the renewable and comprehensive utilization level of resources, and improves human's capacity of self-adjustment, recovery, maintenance and development of the urban ecological system. Ecological civilization city advocates the security and peace of the society, rapid development of the economy and ecological environment of the beautiful harmony, and the productivity of social culture developed, and the beauty and harmony of the ecological environment, an ideal state people are eager to realize when the social culture of an ecological environment consciousness of human being has achieved a certain level and an advanced stage and senior form of development of human residential area.

Ecological civilization city has clear-cut characteristics of the times, which are mainly manifested in the following several aspects:

First is harmony. Harmony here not only refers to harmony of human kind and the nature, but also refers to harmony of relationship between human kinds. Construction of ecological civilization city not only requires a perfect natural environment, but also needs mutual assistance of human kind, an atmosphere in which spirit and soul of human kind is continuously advanced and developed, a group that is imbued with human kindness and cultural flavor and a highest state in which the natural environment is perfect, human kind and the nature gets along well with each other and relationship between human kind is harmonious.

Second is sustainability. Ecological civilization city is one of sustainable development. It not only takes into account interests of the contemporary people, but also takes an overall consideration of demands of the later generation, being sustainable development of environment, society and economy.

Third is high efficiency. Ecological civilization city is an environmental protecting one with "low consumption of energy and low emission". It focuses on circulation and recycle of all sorts of energy so as to make all sorts of waste to be effectively circulated and regenerated, all sorts of energy and information to be effectively employed and all to make the best use of everything, and everybody to give full scope to the talents. 


\subsection{Marxism ecological civilization thought}

\subsubsection{Human kind should be evolved together with the nature and developed in a coordinated way}

Through the ages, human and nature have been getting along with each other in harmony. However, along with the development of the society and driven by the individual selfishness, in order to achieve the purpose of conquering the nature, human kind is damaging more and more seriously the natural environment, and the trace of the damage can be found everywhere.

Marx and Engels attached great importance to the relationship between man and nature, and while they did not put forward the issue of ecological environment, they also mentioned that people and nature should not only be distinguished in contrariety, but also should be harmonious and unified. Engels said, "Interaction of the dead objects in the contains harmony and conflict, whereas interaction of the live objects in the nature not only not only contains the conscious and unconscious cooperation, but also contains conscious and unconscious 'struggle'." Therefore, establishment of a system of harmonious development of man - society - nature is the precondition for sustainable development of human kind. Marx also pointed out that, "socialized man and united producers, will adjust the natural transformation between them and the nature in a reasonable way, put the nature under the control of all of them instead of letting it dominate themselves as a blind force." Thus, it can be found that, realization of the harmony of human and nature is the primary task for human kind to go from the realm of necessity to the realm of freedom.

\subsubsection{Human kind should protect the nature and sponsor the nature instead of damaging the nature}

Marx pointed out: "In practice, the universality of people is manifested as changing the entire nature to the inorganic body of man, firstly regarded as direct living material, and then regarded as the materials, objects and tools of the life activities of man Nature, given that it per se is man, is the inorganic body of man. Man relies on the nature to make a life. That is to say, nature is the body of man to get constantly contacted with it in order not to go death. The so-called link between the body life and spiritual life of man, it also equals to link between the nature and the body itself since it is an integral part of the nature."(Compilation and Translation Bureau of the CPC Central Committee, 1972)

Marx and Engels both opposed to destroy the behavior of damaging the nature. According to them, man and nature are an integral whole, and people should show care for the nature just as they show care for themselves. Marx had ever criticised the behavior of people from Carlsbad to destroy the nature. He said, "We are in Carlsbad, and what we have heard and experienced from everywhere in this city is How it is hot! Besides, here is in shortage of water and it seems that Pur River is going to be sipped up. Since all the trees on the both sides of the river have been cut down, here appears a wonderful situation, that is, the stream is overflowing at a rainy period and is dry at a drought period." (Compilation and Translation Bureau of the CPC Central Committee, 1972) Ignorance, selfishness and greed of human kind make the nature damaged, and naturally the nature will take vengeance on human. On the contrary, if human show care for and protect the nature, then the nature will necessarily pay back the human kind and benefit human kind.

1.2.3 Human kind should act in pursuant to the objective natural rules and go from a realm of necessity to a realm of freedom

Marx once said, "A human plan that is not based on the great natural law will only bring about a disaster." (Compilation and Translation Bureau of the CPC Central Committee, 1972) Human knowledge and understanding in the nature goes from easy to the difficult and undergoes a process of originally inability to use the nature to the currently scientific use of the nature. So long as human kind follow the natural law and abide by the natural law, can they help development of the entire society. Otherwise, they will get revenged by the nature. Engels said, "We have to bear in mind at every moment that, we should neither rule the nature as the conquerors rule the alienages nor like those who stand outside the nature. Instead, we, together with our flesh, blood and head, belong to the nature and exist in the nature. Our mastery of the nature is because we are superior to all other animals and we can correctly understand and use the nature." (Compilation and Translation Bureau of the CPC Central Committee, 1972) Words by Marx and Engels convey a profound truth to us, that is, the human development must be consistent with the natural laws.

\section{Realistic significance of urban ecological civilization construction}

Firstly, urban ecological civilization construction is helpful to enhance the living standard of urban citizens.

A high quality socialism modernization city should be a human-oriented city, one which regards it as the central target to improve the living quality of the citizens. People's quality of life is not only related with the material conditions of life, but also related with the subjective satisfaction with life. Hence, we have to make judgment 
from the subjective and objective aspects on the living quality of an urban citizen.

Objectively speaking, ecological urban construction emphasizes the possibility of all-round, harmonious and sustainable development and attaches great importance to rationality of the city planning. This, to a great extent, makes it focus on the demands of citizens on the objective life, pay attention to the urban traffic convenience, shopping convenience, management efficiency and the most important environmental friendliness.

From a subjective point of view, what the ecological city construction follows is the people-oriented scientific outlook on development. It should not only be concerned with the hardware living conditions of the residents, but also focus on the inner world of the residents and the internal satisfactory elements of residents. In order to make a citizen of the city to really have the internal sense of belonging to the city, construction of the following two aspects is indispensable: a service-type government that is close to citizens and is convenient for citizens and an urban cultural label with clear-cut characteristics. All these two aspects are internal requirements for constructing an ecological city.

Secondly, urban ecological civilization construction is helpful to propel the pace of urban modernization construction

Modernization is not an overnight process, but a project of vital and lasting importance by the CPC and the state. This requires that the modernization construction should not pursue great leap forward development, but should keep the sustainable development. Just as the scientific outlook on development, we should uphold development as the first principle, comprehensiveness, coordination and sustainability as the basic requirement and overall consideration as the basic method.

The construction of ecological city emphases "harmony", namely, harmony between man and nature, and harmony between the city and the society. And harmony is the supposed principle and problem in case to promote the construction of modernization in the city.

Thirdly, urban ecological civilization construction is helpful to enhance the city taste and strengthen urban competitive strength.

In order for a city with high taste to reflect her difference with other cities, the first thing to do is to have its own city culture. A modern city is not the cold combination of machinery and buildings, but a gathering place of residents imbued with life vitality. For the construction of ecological city with the principle of overall consideration, the first thing to do is to take into consideration cultural consistency in urban construction.

Improvement of the urban competitiveness is also closely related with ecological city construction. In the first place, a city with high taste is more capable of attracting excellent talents. In the modernization society today, excellent talents who have received higher education attach more and more importance to the taste and ecology of the city where their permanent residence is registered. In the second place, construction of ecological city is also helpful for the city to attract higher quality investment since financial and internet enterprises that have low pollution, high profits and great developmental potentials prefer to settle their permanent residence in a city with convenient traffic and beautiful ecology. In the fourth place, construction of ecological city is able to stimulate development of tourism in the city and strengthen reputation of the city.

\section{An analysis of the paths for urban ecological civilization construction}

\subsection{Correct handling of several relationships in urban ecological construction}

3.1.1 To correctly deal with the relationship between construction of ecological civilization and development of modern industry and agriculture and to set up scientific outlook on development

The development of human society must rely on development and utilization of natural resources, and, at the same time, must pay attention to protecting a perfect environment, strengthening the construction of ecological civilization and realizing the sustainable development. We should not only pursue development in the process of reasonable development and utilization of resources and protect the environment in the process of development so as to realize high harmony between man and nature and realize co-prosperity and co-existence of man and nature.

The development of modern agriculture must strengthen the vegetation protection, soil and water conservation and reasonable utilization of land resources. Development of modern agriculture has to fight against the optional cultivation, extensive cultivation and destroying the soil structure. We have to adjust measures to local conditions, intensify contral project and improve the land structure. We have to design an engineering project for management of agricultural production according to the ecology principle and the ecological law, coordinate contradictions between development and environment and utilization of resources and protection of resources 
and realize a benign circulation of ecological and agricultural economy.

In the process of industrialization, not in the least can we repeat the old path of treatment after pollution. Instead, we have to take the new type of industrialization path with high scientific and technological content, good economic returns, low consumption of resources, less contamination of environment and human resources fully displayed. We will resolutely overcome the phenomenon of excessive development and waste of resources as a result of quest for output value and ignorance of the environment protection. We have to change the pattern of economic development, attempt to cut down on consumption of resources, strengthen environmental protection, fully exploit the human resources and make ecological civilization become an inexhaustible source of economic development, and realize the sustainable development.

3.1.2 To correctly deal with relationship between construction of ecological civilization and promotion of social harmony and to set up green consumption concept

The construction of ecological civilization and harmonious society construction are dependent on each other and promote each other. The Socialist harmonious society is one in which the human and the nature get along with each other in harmony, whereas ecological civilization is supposed to resolve the fundamental problem of the relationship between man and nature. We have to promote the economic development in rationally developing and utilizing resources, and protect the ecological environment with consciousness in the process of development so as to realize harmonious co-existence of man and man and man and nature and promote the overall progress of the society.

Modern industrial civilization has created unprecedented material wealth in the human history, which makes people enjoy unprecedented convenience and comfort, but this is based on predatory extortion of natural resources. Nowadays, in the society, through the extensive publicity and further development of public ecological civilization creation activities, resources and environment consciousness of the masses has been improved, and humans have been aware that they might be faced up with punishment due to the long-term predatory extortion of natural resources. This promotes people to firmly set up the idea of coordination and harmony between man and nature and the ideas to cherish the nature, to treat well with the nature and to protect the nature and the concept of green civilization consumption.

\subsection{Several suggestions to strengthen construction of urban ecological civilization}

3.2.1 To strengthen education of ecological value concept and to intensify the consciousness of ecological civilization among all citizens

The construction of ecological civilization, the development of the harmonious relation between man and nature, and promotion of the sustainable development of the society cannot go without support of scientific and technological means and security of regulation system, let alone support of cultural consciousness. Ecological moral consciousness is the support and source for the spiritual motive of development of ecological civilization. Therefore, vigorous cultivation of the ecological moral consciousness of all the citizens are of great significance to strengthen the construction of urban ecological civilization.

In order to improve the ecological and moral quality of people, it is necessary to set up a new institutional concept, value concept, economic concept, consumption concept and scientific concept and build a social atmosphere to cultivate the ecological and moral consciousness of all citizens. In addition, it is necessary to set up a perfect environmental protection education mechanism, especially the aspects of education in the school and we should pay special attention to cultivation and improvement of the ecological and moral consciousness of young people. Only if people are aware of the importance of ecological protection at an early age and set up a correct ecological value concept and moral concept, is it possible to construct a solid ecological barrier in the bottom of their heart and to form the perfect ecological and moral behaviors to practically prevent the tragedy of damage to the ecosystem to happen again.

\subsubsection{To vigorously development the circular economy and to transform the pattern of economic development}

Vigorous development of circular economy can fundamentally resolve the sharp conflict between economic growth and resource environment that is encountered in the process of economic development and coordinate relationship between social economy and resource environment. At the same time, it helps to improve quality of economic growth. It is the realistic requirement to transform the pattern of economic growth, the concrete reflection of taking the new type of industrialization path and is also the necessary requirement for construction of ecological civilization.

Resources are limited. To meet the need of sustainable development of human, it is a must to advocate the concept of saving resources in the whole society and try hard to form a production mode, industrial structure and 
consumption mode that help to the save sources and reduce pollution. We have to vigorously develop and promote advanced application technology to save, replace and circularly employ resources and control pollution, develop clean energy and renewable energy, set up scientific and reasonable energy and resource utilization system and improve efficiency of energy and resource utilization.

3.2.3 To set up corresponding policy and regulation system and to form a strong and vigorous security mechanism

In terms of policy, we should resolve the issue of environment from the strategic perspective of urban development. It is urgent to draw up economic policy system about such aspects as price, finance, taxation and land of environmental protection, conduct urban ecological function regionalization, guide all regions to select the development direction in a reasonable way an form distinctive development patterns. Furthermore, it is necessary to optimize pattern of industry, adjust industrial structure and transform the development mode. In addition, it is necessary to improve the legal system that is helpful for saving energy and resources and protecting the ecological environment and bring construction of ecological civilization into the track of governance in pursuant to the law. At the same time, through the establishment and implementation of accountability system for violation of rules and regulations of ecological environment, we have to stimulate and strengthen the responsibility consciousness of ecological civilization construction among the leading cadres at all levels, the environmental protection law enforcement personnel, environmental protection industry unit and its employees and the masses.

It has been clearly stipulated in the Report to the Seventeenth National Congress of the Communist Party of China that, "It is necessary to make the concept of ecological civilization firmly established in the whole society". Thus, we have to insist on equal emphasis on economic development and environmental protection and resources saving and make the living standard of people continuously improved, the production capacity of enterprises continuously increased, the social and ecological environment continuously improved and realize faster and better development of urban economic society.

\section{References}

Compilation and Translation Bureau of the CPC Central Committee. (1972). Karl Marx and Frederick Engels, Vol. 42. People's Publishing House, pp.95.

Compilation and Translation Bureau of the CPC Central Committee. (1972). Karl Marx and Frederick Engels, Vol. 32. People's Publishing House, pp.384.

Compilation and Translation Bureau of the CPC Central Committee. (1972). Karl Marx and Frederick Engels, Vol. 31. People's Publishing House, pp.251.

Compilation and Translation Bureau of the CPC Central Committee. (1972). Karl Marx and Frederick Engels, Vol. 20. People's Publishing House, pp.519.

Fang, Shinan. (2006). Building up a Natural Foundation of Harmonious Society from the Perspective of Eco-civilization. Journal of Shandong University of Science \& Technology (Social Sciences), (2).

Hu, Jintao. (2007). Hold High the Great Banner of Socialism with Chinese Characteristic and Strive for New Victories in Building a Moderate Prosperous Society in all Respects --- Report to the Seventeenth National Congress of the Communist Party of China. People's Daily, October 15.

Liu, Hongkai \& Zhang, Yuming. (2006). Constructing City Ecological Culture and City Green Civilization. Daqing Social Sciences, (6).

Zhang, Qinglan \& Liu, Qinmin. (2007). Ecological Civilization: Foundation of Socialism Harmonious Society. Journal of Hohai University (Philosophy and Social Sciences), (1). 